\title{
POLÍTICAS PÚBLICAS EDUCACIONAIS, GRADAÇÃO DAS LEIS E DISCURSO LEGAL
}

\author{
VICENTE DE PAULO MORAIS JUNIOR*
}

\begin{abstract}
RESUMO
A presente pesquisa teve como objetivo estabelecer a relação entre políticas públicas eseu respectivo ciclo, gradação das leis e discurso legal. Trata-se de uma pesquisa bibliográfica que trilhou aspectos técnicos, científicos e jurídicos. Constatou-se que existe uma relação intrínseca entre o ciclo das políticas públicas, gradação das leis e discurso legal. Tal relação permite vislumbrar um caminho metodológico para pesquisa, análise e discussão das temáticas exibidas.

Palavras-chave: Políticas públicas.Gradação das leis.Discurso legal.
\end{abstract}

\begin{abstract}
The present research aimed to establish the relationship between public politics and their respective cycle, gradation of the laws and legal speech. A bibliographical research has covered technical, scientific and legal aspects. It wasfound that there is an intrinsic relation between the cycle of the public politics, gradation of the laws and legal speech. This relationship allows us to glimpse a methodological path for research, analysis and discussion of the presented themes.
\end{abstract}

Key-words: Public politics. Law grading.Legal speech.

* Vicente de Paulo Morais Junior é Doutorando em Educação na Universidade Metodista de São Paulo (UMESP) e Mestre em Educação pela mesma Universidade. Atualmente, exerce a função de Professor da Rede Pública do Estado de São Paulo e professor do curso de Pedagogia da Faculdade Bilac (São José dos Campos/SP). Contato: vicentemjunior@hotmail.com 


\section{INTRODUÇÃO}

Ao iniciar a pesquisa em relação a conceitos e definições de políticas públicas, logo deparou-se com a "polissemia do conceito" que envolve a temática. Inúmeros termos e "afluentes" foram sendo apresentados na bibliografia consultada, trazendo muito mais um emaranhado de definições do que um aclarar de conceitos. Mesmo com todo esse "emaranhado", ora obscuro, ora esclarecedor, saltou aos olhos a intrínseca relação entre políticas públicas, em especial as educacionais, gradação das leis e discurso legal.

Observou-se que essa intrínseca relação foi apresentada na bibliografia consultada em traços superficiais, como peças de diferentes quebra-cabeças. A fim de sair da superficialidade que envolve políticas públicas e gradação das leis, usando peças de um mesmo quebra-cabeça, a presente pesquisa propõe uma discussão técnica, científica, e porque não jurídica, que faça eclodir das entrelinhas das políticas públicas, discurso legal e gradação das leis um possível caminho metodológico para análise, discussão e reflexão dessa temática.

Buscou-se, assim, metaforizar o ciclo das políticas públicas, conforme Boletim REPENTE, ${ }^{1}$ combinado a referenciais jurídicos que respaldam as discussões que envolvem a gradação das leis. Além disso, destacou-se a presença das políticas propostas e políticas de fato (MAINARDES, 2006).

Deste modo, pretende-se, ao discutir tais temáticas, encontraruma "chave" para entender o elo ou a fusão, entre política proposta e política de fato.

\section{POLÍTICAS PÚBLICAS: NASCER, CRESCER, MATURAR E TRANSFORMAR}

Iniciamos as discussões metaforizando as políticas públicas como andaimes inseridos em um processo de construção, não

\footnotetext{
O Boletim REPENTE é publicado pelo Pólis (ONG fundada em 1987 - São Paulo/SP) desde 1996, voltado para lideranças dos movimentos sociais. Os boletins impressos têm como objetivo abordar questões e temas diversos de interesse da sociedade civil. Disponível em: $<$ http://polis.org. br/>. Acesso em: 25 de outubro de 2017.
} 
de engenharia civil, e sim da sociedade (BRUNO, 2013). Ainda fazendo uso do termo andaimes para as políticas públicas no processo de construção da sociedade, Cortes e Lima frisam que tais políticas serão compostas por ações, atividades, programas, entre outros, estabelecendo assim uma interação entre o Estado e a sociedade $(2012$, p.47). O Boletim REPENTE completa a abordagem, trazendo para a discussão, que a política pública acaba por ser o “(...) principal instrumento utilizado para coordenar programas e ações públicas” (REPENTE, 2006, p.1). Logo conclui-se que, conforme Souza, planos, programas e projetos são nada menos que os desdobramentos das políticas públicas e estas quando “(...) postas em ação, são implementadas, ficando submetidas a sistemas de acompanhamento e avaliação" (2006, p.26). Não nos sobram dúvidas em mencionar, então, que as políticas públicas caracterizam-se como o exercício do poder público na relação Estado e sociedade (OLIVEIRA, 2011, p.68; SOUZA, 2006, p.25). Porém, vale ressaltar que tais conceitos vão:

(...) além da ideia de que uma política pública é simplesmente uma intervenção do Estado numa situação social considerada problemática. Mais do que isso, penso a política pública como uma forma contemporânea de exercício do poder nas sociedades democráticas, resultante de uma complexa interação entre o Estado e a sociedade, entendida aqui num sentido amplo, que inclui as relações sociais travadas também no campo da economia. Penso, também, que é exatamente nessa interação que se definem as situações sociais consideradas problemáticas, bem como as formas, os conteúdos, os meios, os sentidos e as modalidades de intervenção estatal (GIOVANNI, 2009, p.5-6) [grifos do autor].

A política pública também pode, em um sentido mais amplo, ser caracterizada como tomada de decisões (REPENTE, 2006, p.3). Logo, estabelecer uma relação entre Estado e sociedade com base em "andaimes", faz que a política pública possa ser encarada como mecanismo ou campo de conhecimento que coloca o "governo em ação" (SOUZA, 2006, p.26). 
Vale ressaltar que os andaimes estarão fortes e sólidos, desde que exista participação de todos os atores ${ }^{2}$ envolvidos em uma política pública. Porém, observamos muito mais uma "cultura paroquial" com os seus respectivos súditos, havendo passividade dos atores diretamente envolvidos na política pública, do que uma cultura de participação"3 (FREY, 2000, p.237). Silva e Melo mencionam que não havendo a participação dos atores diretamente envolvidos com a política pública proposta, esta por sua vez passa a ser visualizada, conforme os autores como top down, ou políticas impostas de "cima para baixo" (2000, p.5).

O Boletim REPENTE aponta que as políticas públicas “(...) nascem, crescem, maturam-se e transformam-se" (2006, p.2). Usaremos a lógica proposta pelo Boletim REPENTE para pautar a discussão que segue.

Ao analisar o "nascimento" da política pública, Mainardes, sabiamente, contribui apontando que:

[...] a produção de políticas inicia-se com a identificação de um problema e a construção de uma agenda. Nesse sentido, a tomada de decisão não representa o ponto de partida das políticas públicas. Ela é precedida de ações, disputas e processos de negociação (2009, p.9-10).

A partir da elaboração e publicação do texto legal, tendo como principal referencial a gradação das leis, as políticas

2 Conforme Caldas e Lopes, considera-se como atores "os grupos que integram o Sistema Político, apresentando reivindicações ou executando ações, que serão transformadas em Políticas Públicas". Os autores ainda irão realizar uma divisão no "grupo de atores" em: os "estatais" (oriundos do Governo ou do Estado) e os "privados" (oriundos da Sociedade Civil - imprensa, centros de pesquisa, associações da Sociedade Civil Organizada [SCO], entidades de representação empresarial, sindicatos patronais, sindicatos de trabalhadores, outros) (2008, p.8-9).

3 O autor faz uso dos termos "cultura paroquial" e "cultura de participação" a partir da proposta de Almond e Verba (1963), que por sua vez apresentam “(...) em seus estudos sobre 'civic culture', três tipos ideais de cultura política, os quais correspondem a diferentes fases de modernização do desenvolvimento de sociedades (...)" (FREY, 2000, p.237). 
públicas iniciam o seu processo de crescimento. Observa-se uma fusão entre o processo de crescimento e maturação, pois a maturação, como bem lembra o Boletim REPENTE, está diretamente ligada à implementação da política pública, que representa um movimento "retroalimentador" da própria política pública. Essa retroalimentação proporciona uma relação intrínseca entre implantação e implementação, pois seu processo de maturação cria novas políticas públicas (SILVA e MELO, 2000, p.11).

Além da abordagem que envolve o "nascer e crescer" da política pública convém, por oportuno, destacar que nas entrelinhas desse movimento: "a política proposta, a política de fato (textos políticos e legislativos) e a política em uso" (MAINARDES, 2006, p.95). Em relação à“política de fato”, destaca-se ainda a gradação das leis como aspecto estruturante de todo esse movimento.

Sincronizado a esse movimento, a transformação proposta pelo Boletim REPENTE virá com o processo de avaliação. Vale ressaltar que a avaliação das políticas públicas terá ao menos dois eixos: avaliação da política pública em si e suas características e avaliação dos impactos das políticas públicas aos seus respectivos interessados (CASTRO, 1989, p.3). Observa-se ainda que a avaliação da política pública não deve ocorrer apenas no fim de um processo. $\mathrm{O}$ investimento em avaliações durante o processo de implementação solidifica o próprio refinamento da política pública em questão.

\section{POLÍTICAS PÚBLICAS EDUCACIONAIS, DISCURSO OFICIAL E GRADAÇÃO DAS LEIS}

A análise da inter-relação entre gradação das leis e discurso legal torna-se preponderante para a discussão e reflexão sobre o nascimento, crescimento, maturação e transformação das políticas públicas.

A partir dessa abordagem é possível identificar e, por conseguinte, analisar a política proposta, a política de fato (textos políticos e legislativos) e a política em uso.

Evidentemente que, ao discutirmos a elaboração da política de fato com seus textos políticos, aqui denominados como 
discurso legal, carece, a priori,realizar uma análise conceitual e técnica e, por que não dizer jurídica, de todos esses elementos.

Ao descrever as hierarquias das leis no país e suas devidas gradações, Soares (2007) bem lembra que todas as legislações no país estão hierarquicamente atreladas à Constituição Federal de 1988. Porém:

Cada Estado tem uma Constituição própria, e um conjunto de leis estaduais, que deve se enquadrar nas federais. Da mesma forma, os Municípios, ao elaborar suas leis orgânicas e as demais leis, devem conformá-las de modo a não contrariar a Lei Estadual e a Federal (2007, p.6).

Em relação à hierarquia das leis, Soares aponta:

Hierarquia das leis no Brasil:

1. Constituição

2. Emenda à constituição

3. Lei complementar

4. Lei ordinária ou código ou consolidação

5. Lei delegada

6. Decreto legislativo

7. Resolução

8. Decreto

9. Instrução normativa

10. Instrução administrativa

11. Ato normativo

12. Ato administrativo

13. Portaria

14. Aviso (2007, p.6)

Essa hierarquia é denominada como atos normativos, sendo considerado como atos normativos secundários a partir do item '7. Resoluções' (SÃO PAULO, 2008). Além dos atos normativos, caracterizados na citação, teremos também os atos processuais.

Vale ressaltar que os atos normativos e processuais, têm como principal característica permitir a execução das leis, sendo 
“(...) sempre o detalhamento de como executar, cobrar, dispensar serviços, verificar aplicação legal (...)” (SOARES, 2007, p.6). Em relação aos atos normativos, podemos defini-los como documentos legais que estabelecem normas ou regras com vistas à correta aplicação da lei (SÃO PAULO, 2008, p.30).

Os atos administrativos que aqui serão analisados estão categorizados como Deliberação, Indicação, Resolução, Instrução e Portaria.

Assim, entende-se Resolução como:

Ato normativo com a finalidade de complementar e normatizar legislação tributária, orçamentária, financeira e de recursos humanos [outros], além de dispor sobre todos os assuntos de competência da Sefaz ${ }^{4}$ [Secretarias de Estado]. A resolução tem como destino o público em geral ( $\mathrm{S}$ ÃO PAULO, 2008, p.38).

Seguindo a mesma linha de conceituações, temos como Deliberação:

Ato que tem como finalidade decidir, impor ordem ou estabelecer uma medida. Também destinada ao público em geral, a deliberação é semelhante à resolução, tanto no que diz respeito à estrutura quanto ao conteúdo. A diferença entre ambas está na autoridade competente que expede a deliberação, emanada de órgão colegiado (conselho administrativo ou deliberativo), no qual o poder de decisão é igualitário entre seus componentes, não centralizado numa só pessoa(SÃO PAULO, 2008, p.49).

Em relação à Instrução, temos como "orientação feita por diretor de órgão público para execução de atos normativos, em que faz menção aos artigos, cujos conteúdos estão sendo detalhados e regulamentados" (UNICAMP, 2011, p.20), ou ainda como:

4 Entende-se como Sefaz: Secretaria de Estado da Fazenda (São Paulo/ Estado). 
(...) ordens escritas e gerais a respeito do modo e forma de execução de determinado serviço público, expedidas pelo superior hierárquico com o escopo de orientar os subalternos no desempenho das atribuições que lhes estão afetas e assegurar a unidade de ação no organismo administrativo. As instruções não podem contrariar a lei, o decreto, o regulamento, o regimento ou o estatuto do serviço, uma vez que são atos inferiores, de mero ordenamento administrativo interno (UFSC, s.d.).

As Indicações podem ser caracterizadas como encaminhamento de propostas ou sugestões à presidência ou às autoridades de órgão ou à comissão competente para tomarem conhecimento e darem solução (USP, 1997, p.21).

Já as Portarias, são atos normativos:

(...) com finalidade de estabelecer procedimentos relativos a pessoal, organização e funcionamento de serviços, além de orientação quanto à aplicação de textos legais. A portaria é destinada ao público em geral e a unidades internas (SÃO PAULO, 2008, p.40).

Finalizando a conceituação de atos normativos e processuais, temos para os Pareceres:

(...) são manifestações de órgãos técnicos sobre assuntos submetidos à sua consideração. $\mathrm{O}$ parecer tem caráter meramente opinativo, não vinculando a Administração ou os particulares à sua motivação ou conclusões, salvo se aprovado por ato subsequente. Já, então, o que subsiste como ato administrativo não é o parecer, mas, sim, o ato de sua aprovação, que poderá revestir a modalidade normativa, ordinatória, negocial ou punitiva (UFSC, s.d.).

Destaca-se a máxima evidenciada por Mainardes, quando este aponta que, em relação à metodologia de pesquisa para e com políticas públicas, tem-se a necessidade de se pesquisar 
tanto o aspecto macrocontextual quanto o microcontextual (2006, p.100).

Esse campo de atuação metodológica de pesquisa em políticas públicas é devidamente destacado por Oliveira, quando esta menciona que:

(...) a discussão acerca das políticas públicas em educação ou a ela dirigidas, ou ainda as políticas públicas que se relacionam com a educação, ultrapassa em muito o domínio da pedagogia, das teorias pedagógicas e exige a contribuição de outros campos de conhecimento para sua análise(2011, p. 68).

Para além da pedagogia, as políticas públicas educacionais carecem de uma análise técnico-científica, além de uma análise jurídica, para que assim seja possível entender o ciclo de nascimento, crescimento, maturação e transformação. A partir dessa lógica metodológica, as políticas públicas podem ser capturadas como objetos de estudo no momento da sua concepção ou formulação; de sua implantação ou execução e no seu monitoramento ou avaliação (FERREIRA e OLIVEIRA 2013, p.8).

\section{CONSIDERAÇÕES FINAIS}

$\mathrm{Na}$ trilha desta pesquisa, observou-se a necessidade de conhecer as políticas públicas em seu ciclo organizacional, que aqui foi abordado como nascimento, crescimento, maturação e transformação. Esse ciclo nos permite ainda observar a relação intrínseca existente entre o processo de implantação e implementação. Implementações geram outras implantações.

No processo de implantação, o discurso oficial, amparado pela gradação das leis, transforma política proposta em política de fato. Essa transformação tem como premissa a limitação legal das funções a atribuições de atos normativos e administrativos. Dessa forma, observa-se que as políticas públicas necessitam de um conjunto de atos normativos e administrativos para que, de fato, consigam traduzir no discurso oficial a ideia primeira, 
expressa na política proposta ou no seu nascimento, como propõe o Boletim REPENTE.

Sendo assim, as políticas públicas educacionais necessitam, ao serem pesquisadas, ter como organização metodológica a identificação do conjunto de atos normativos e administrativos que a compõem.

A chave para entender o elo, ou a fusão, entre política proposta e política de fato, ou ainda direito e demanda de política pública e discurso oficial, está na compreensão da gradação das leis e suas respectivas funcionalidades.

\section{REFERÊNCIAS}

BRUNO. Lúcia Emília Nuevo Barreto. Poder político e sociedade: qual sujeito, qual objeto?. In: FERREIRA, Eliza Bartolozzi e OLIVEIRA, Dalila Andrade. Crise da escola e políticas educativas. Belo Horizonte: Autêntica Editora, 2013.

CALDAS, Jefferson Wahrendorff e LOPES, Brenner (Org.). Políticas Públicas: conceitos e práticas. Belo Horizonte: SEBRAE/MG, 2008.

CASTRO, Maria Helena Guimarães de. Avaliação de políticas e programas sociais. Caderno de Pesquisa, Núcleo de estudos de políticas públicas, Campinas, n.12, 1989.

CORTES, Soraya Vargas e LIMA, Luciana Leite. A contribuição da sociologia para a análise de políticas públicas. Lua Nova, São Paulo, n. 87, 2012. DIREITO VIRTUAL. Dicionário Jurídico. Disponível em: < http://direitovirtual.com.br/dicionario/>. Acesso em: 7 de janeiro de 2015.

FERREIRA, Eliza Bartolozzi e OLIVEIRA, Dalila Andrade. Crise da escola e políticas educativas. Belo Horizonte: Autêntica Editora, 2013.

FREY, Klaus. Políticas públicas: um debate conceitual e reflexões referentes à prática da análise de políticas públicas no Brasil. Planejamento e Políticas Públicas/IPEA,[s.l.] , n.21, jun. 2000.

GIOVANNI, Geroldo di. As estruturas elementares das políticas públicas.Caderno de Pesquisa,Núcleo de estudos de políticas públicas - NEPP, Campinas, n.82, 2009.

MAINARDES, Jefferson. A abordagem do ciclo de políticas e suas contribuições para a análise da trajetória de políticas educacionais. Atos de Pesquisa em Educação, Blumenau, v. 1, n. 2, mai./ago. 2006.

.Análise de políticas educacionais: breves considerações teórico-metodológicas. CONTRAPONTOS, Itajaí, v. 9, n. 1, jan./abr. 2009.

OLIVEIRA, Dalila Andrade. As políticas públicas em educação e a pesquisa acadêmica.In: OLIVEIRA, Dalila Andrade e DUARTE, Adriana(Org). Políticas Públicas e Educação: regulação e conhecimento. Belo Horizonte: Fino Traço Editora, 2011. 
REPENTE, Polis: Instituto de Estudos, formação e assessoria em políticas públicas. Política pública como garantia de direitos (boletim). São Paulo, n.26, dez. 2006.

SÃO PAULO (ESTADO). Secretaria da Fazenda. Manual de redação dos atos oficiais e de comunicação da Secretaria da Fazenda. São Paulo: Fazesp, 2008. SILVA, Pedro Luiz Barros e MELO, Marcus André Barreto de. O processo de implementação de políticas públicas no Brasil: características e determinantes da avaliação de programas e projetos. Caderno de Pesquisa, Núcleo de estudos de políticas públicas, Campinas, n.48, 2000.

SOARES, Rosinethe Monteiro. Hierarquia das leis (2007). Disponível em: < http://www.buscalegis.ufsc.br/revistas/files/anexos/15967-15968-1-PB.pdf $>$. Acesso em 7 de janeiro de 2015.

SOUZA, Celina. Políticas Públicas: uma revisão da literatura. Sociologias, Porto Alegre, v.8, n. 16, jul./dez. 2006.

UNIVERSIDADE DE SÃO PAULO(USP). Glossário de Espécies/Formatos e Tipos Documentais da Universidade de São Paulo. São Paulo, 1997. Disponível em: < http://www.usp.br/sausp/gestao/download/glossario.pdf $>$. Acesso em: 7 de janeiro de 2015.

UNIVERSIDADE ESTADUAL DE CAMPINAS(UNICAMP). Manual de recomendações para a produção de atos administrativos. ARQUIVO CENTRAL DO SISTEMA DE ARQUIVOS. Campinas, out. 2011.Disponível em: < http://www.siarq.unicamp.br/siarq/images/siarq/arquivos setoriais/ manual_atos_administrativos.pdf $>$. Acesso em: 7 de janeiro de 2015.

UNIVERSIDADE FEDERAL DE SANTA CATARINA(UFSC). Legislação: Glossário. Disponível em: <http://legislacao.ufsc.br/glossario/>. Acesso em: 7 de janeiro de 2015. 